\title{
Role of melt injection and mixing in formation of Archean chromitite in anorthosites: Evidence from the Sittampundi anorthosite complex, southern India
}

\author{
HAI-LONG HE ${ }^{1}$, P.M. GEORGE ${ }^{2}$, \\ K. SAJEEV ${ }^{3}$, MING-GUO ZHAI ${ }^{1,2}$
}

${ }^{1}$ State Key Laboratory of Lithospheric Evolution, Institute of Geology and Geophysics, Chinese Academy of Sciences, Beijing, 100029, P.R. China; (hehail@mail.sysu.edu.cn) ${ }^{2}$ State Key Laboratory of Continental Dynamics, Department of Geology, Northwest University, Xian 710069, China

${ }^{3}$ Centre for Earth Sciences, Indian Institute of Science, Bengalore 560012, India

Chromitite and anorthosite interlayers occur in many layered intrusions and the Archean anorthosite complexes. The Neoarchean Sittampundi anorthosite complex in southern India is composed of white anorthosite, dark anorthosite, minor gabbro and pyroxenes granulite. Plenty of chromitite layers are hosted in anorthositic rocks, in sharp contact with each other. Coarse-grained amphibole and plagioclase in the chromitites are also surrounded by interstitial Cr-spinel and amphibole to form embayment textures along their rims. Besides, REE patterns of the coarse-grained amphibole and ${ }^{87} \mathrm{Sr} /{ }^{86} \mathrm{Sr}$ isotope values of plagioclase in chromitites and that in hosting anorthosite are similar, implying that coarse silicate minerals in the chromitites were captured from the anorthosite host. In contrast, High-Mg\# orthopyroxene megacrysts are present in chromitite but absent in anorthositic rocks. These orthopyroxenes are commonly optically continuous, but are crosscut and surrounded by interstitial Crspinel and amphibole in their core and rim, respectively. The absence of orthopyroxene in anorthosite indicates that orthopyroxene was probably formed earlier in the deeper magma chamber(s), and partially remelted when it entered the extant magma chamber. Such relationships strongly suggest that Cr-spinel was saturated through the mixing of an anorthositic mush with a replenished (more primitive) magma. The addition of $\mathrm{Cr}_{2} \mathrm{O}_{3}$ from the replenished magma (especially from the orthopyroxene xenocrysts) and $\mathrm{SiO}_{2}$ from the anorthositic crystal mush would have pushed for the $\mathrm{Cr}$-spinel saturation and triggered chromitite formation. The high $\mathrm{Al}$ feature of $\mathrm{Cr}$-spinel is likely to be a function of plagioclase remelting, which increased the amount of $\mathrm{Al}^{3+}$ in the mixed magma. 